S E C Pretlove ${ }^{(1)}$ BSc(Hons) MSc(Arch) PhD MBEng MCIOB

T Oreszczyn ${ }^{(2)}$ BSc PhD CEng MCIBSE MinstE

I Ridley ${ }^{(2)}$ BSc MSc PhD

T Wilkinson ${ }^{(3)(4)}$ BSc(Hons) MSc DIC

D Crowther $^{(4)}$ MA DipArch PhD

(1) London South Bank University, 103 Borough Road, London, SE1 0AA

(2) The Bartlett School of Graduate Studies, University College London, London, WC1E 6BT

(3) Insect Research \& Development Limited, Cambridge

(4) The Martin Centre, University of Cambridge, Cambridge

\title{
A steady state model for predicting hygrothermal conditions in beds in relation to house dust mite requirements
}

\begin{abstract}
This paper describes the development, testing and validation of a simple steady state hygrothermal bed model that predicts conditions of temperature and humidity within beds so that the impact on dust mite populations can be assessed.

Monthly conditions of temperature and relative humidity within the bedroom are predicted using the BREDEM-8 domestic energy model, which has been adapted to incorporate a moisture production and relative humidity algorithm. These conditions are then used as bed boundary conditions for the simple steady state BED3 model which is used to determine the average monthly conditions of temperature and relative humidity within the bed.
\end{abstract}

The model has been validated using monitored bedroom and bed data for a full year in three dwellings and the results show that the steady state model predicts monthly bedroom and bed hygrothermal conditions with a high degree of accuracy.

A sensitivity study of the model has also been carried out to assess the impact of changes in input parameters of the model on the bed hygrothermal conditions. The impact of climate change has also been assessed using future climate change scenarios. 


\section{Nomenclature}

$\begin{array}{ll}\mathrm{A}_{\text {body }} & \text { Surface area of the body }\left(\mathrm{m}^{2}\right) \\ \mathrm{A}_{\text {head }} & \text { Surface area of the head }\left(\mathrm{m}^{2}\right) \\ \mathrm{C} & \text { Convective heat losses from the uncovered head }(\mathrm{W}) \\ \mathrm{d}_{\text {cover }} & \text { Thickness of the bed cover }(\mathrm{m}) \\ \mathrm{E}_{\mathrm{d}} & \text { Heat losses by skin diffusion }(\mathrm{W}) \\ \mathrm{E}_{\text {re }} & \text { Latent respiration heat losses }(\mathrm{W}) \\ \mathrm{h}_{\mathrm{c}} & \text { Convective heat transfer coefficient for the head }\left(\mathrm{Wm}^{-2} \mathrm{~K}^{-1}\right) \\ \mathrm{k}_{\text {cover }} & \text { Thermal conductivity of the bed cover }\left(\mathrm{Wm}^{-1} \mathrm{~K}^{-1}\right) \\ \mathrm{L} & \text { Dry respiration heat losses }(\mathrm{W}) \\ \mathrm{M} & \text { Total metabolic heat gain }(\mathrm{W}) \\ \mathrm{Q}_{\text {bed }} & \text { Sensible metabolic heat gains per unit area of body }\left(\mathrm{Wm}^{-2}\right) \\ \mathrm{R} & \text { Radiant heat losses from the uncovered head }(\mathrm{W}) \\ \mathrm{R}_{\text {s.cover }} & \text { Surface thermal resistance of the cover }\left(\mathrm{m}^{2} \mathrm{KW} \mathrm{K}^{-1}\right) \\ \mathrm{RH}_{\text {bed }} & \text { 24 hour mean relative humidity in the bed core }(\%) \\ \mathrm{RH}_{\text {unocc }} & \text { Relative humidity in the unoccupied bed }(\%) \\ \mathrm{RH}_{\text {occ }} & \text { Relative humidity in the occupied bed }(\%) \\ \mathrm{SVP}_{\text {skin }} & \text { Saturated vapour pressure at skin temperature }(\mathrm{Pa}) \\ \mathrm{t}_{\text {occ }} & \text { Number of hours that the bed is occupied each day }(\mathrm{h}) \\ \mathrm{T}_{\text {bed }} & \text { 24 hour mean bed core temperature }\left({ }^{\circ} \mathrm{C}\right) \\ \mathrm{T}_{\text {head }} & \left.\text { Temperature of the head ( }{ }^{\circ} \mathrm{C}\right) \\ \mathrm{T}_{\text {room }} & \text { Temperature of the room }\left({ }^{\circ} \mathrm{C}\right) \\ \mathrm{U}_{\text {mattress }} & \text { Thermal transmittance of the mattress }\left(\mathrm{Wm}{ }^{-2} \mathrm{~K}^{-1}\right) \\ \mathrm{VP}_{\text {room }} & \text { Partial pressure of water vapour in the room air }(\mathrm{Pa}) \\ \mathrm{VP}_{\text {bed }} & \text { Partial pressure of water vapour in the bed }(\mathrm{Pa}) \\ \mathrm{VR}_{\text {body }} & \text { Vapour resistance of the human body }\left(\mathrm{Nskg}{ }^{-1}\right) \\ \mathrm{VR}_{\text {mattress }} & \text { Vapour resistance of the mattress }\left(\mathrm{Nskg}{ }^{-1}\right) \\ \mathrm{VR}_{\text {cover }} & \text { Vapour resistance of the cover }\left(\mathrm{Nskg}{ }^{-1}\right) \\ \Delta \mathrm{T} & \text { Temperature difference between the core of the bed }\left(34^{\circ} \mathrm{C}\right) \text { and the } \\ & \text { ambient room temperature }\left({ }^{\circ} \mathrm{C}\right)\end{array}$




\subsection{Introduction}

There is clear evidence that house dust mite faeces are a major causal factor affecting the health of a significant proportion of the population, especially children ${ }^{(1)}$ as well as many $\operatorname{adults}^{(2)}$. There is also clear evidence that the population of mites in dwellings is affected by the conditions of temperature and relative humidity and that mite populations can be controlled by modifying the hygrothermal conditions in dwellings $^{(3)(4)}$. Being able to accurately model the conditions in dwellings and beds therefore enables us to look at the impact that changes in the design and use of a dwelling are likely to have on the size of the population of house dust mites in a bed and hence the health of the occupants.

This paper describes a recently completed multi-disciplinary government (EPSRC) funded project in which two models, a complex three-dimensional model and a simple steady state model, have been developed to predict hygrothermal conditions within occupied beds. The complex model is described in detail elsewhere ${ }^{(5)}$. The simple steady state model, which has been developed for potential use by practitioners such as building designers, energy consultants, environmental health officials and policy makers is described in this paper.

\subsection{Modelling hygrothermal conditions in the dwelling}

In order to predict the temperature and relative humidity within the bedroom an existing hygrothermal model is used, Condensation Targeter II. The Condensation Targeter II model incorporates both a thermal model and a moisture model and is described in detail elsewhere ${ }^{(6)}$. 
The thermal model used in Condensation Targeter II is BREDEM-8, the monthly domestic energy model produced and validated by the Building Research Establishment (BRE) $)^{(7)}$.

The moisture model used in Condensation Targeter II is Loudon's simple steady state moisture balance calculation ${ }^{(8)}$. This moisture model assumes that the dwelling is a single zone and does not account for moisture adsorption or desorption. The Condensation Targeter II model incorporates a sophisticated moisture production rate algorithm, which has been developed following a detailed review of moisture production rates in dwellings ${ }^{(9)}$.

Figure 1 shows the typical range of moisture production rates per person for different activities based upon data found in published literature ${ }^{(9)}$.

The Condensation Targeter II model has been validated by comparing the measured bedroom conditions in 36 dwellings with those predicted by the model. For the 36 dwellings tested, the mean deviation of the model predictions of relative humidity from the actual relative humidity was just over $5 \%$ whilst the mean deviation of the model predictions for temperature from the actual temperature was just under $1{ }^{\circ} \mathrm{C}^{(6)}$.

\subsection{Modelling hygrothermal conditions in the bed}

This section describes in detail the development of the BED3 model and the formulae that it uses to determine the monthly average values of bed core temperature and relative humidity, given the room conditions predicted by Condensation Targeter II. To avoid confusion it is necessary to define the bed core. The bed core is the central space of the bed occupied by the sleeper, not the core of the mattress. 


\subsection{Model development}

Two earlier models (BED1 and BED2) were tried before BED3 was used. The original BED1 model incorporated a simple thermal heat balance equation which was used to determine the average monthly temperature rise in the occupied bed based upon a fixed occupant heat gain and a thermal resistance to upward and downward heat flow. It was assumed that this average temperature rise was the same throughout the year. The BED1 model also incorporated a simple moisture balance equation, which determined the average monthly vapour pressure excess in the occupied bed based upon the average occupant rate of moisture input. This vapour pressure excess was then added to the room vapour pressure to give the occupied bed vapour pressure and the bed relative humidity was then determined, also using the bed temperature.

Tests of the BED1 model showed, for a typical domestic dwelling, that the predictions of relative humidity were too high, typically in the winter months $100 \%$, and always significantly higher than the ambient levels of relative humidity within the bedroom. The predictions of temperature were also suspect because of the assumption that there would always be a fixed temperature rise within the bed each month. In reality the difference between the occupied bed temperature and the ambient room temperature is going to be greater during the winter months than the summer months.

Significant improvements to the BED1 model led to the development of the BED2 model. The main modification in the BED2 model was the assumption that the occupied bed had a stable temperature of $34^{\circ} \mathrm{C}$ (skin temperature for thermal comfort). The average temperature within the bed was calculated using the number of hours per day that the bed is occupied at a temperature of $34^{\circ} \mathrm{C}$, together with the 
number of hours per day that the bed is unoccupied. During this period the bed temperature is assumed to be the same as the room temperature. The moisture balance calculation in the BED2 model remained the same as in the BED 1 model.

Tests on the BED 2 model showed it to be significantly more accurate at predicting the bed conditions of temperature and relative humidity than the BED1 model. It predicted average bed relative humidity values lower than ambient room relative humidity values, which is what was found in the monitoring of real bed conditions. However, the assumption that the occupied bed temperature is constant for a fixed thickness of the bed cover is flawed and so further improvements were made, which led to the development of the BED3 model.

The BED3 model overcomes the problems encountered in the BED 2 model in that it adjusts the thickness of the cover so that the bed comfort temperature is maintained at a constant $34^{\circ} \mathrm{C}$. The moisture calculation then uses the varying monthly cover thickness in the calculation of the moisture in the bed and the bed core relative humidity. The model assumes that no sweating takes place.

Comfort within the bed is always assumed when it is occupied. In reality the thickness of the cover on a bed will not vary each month. In most real situations the cover thickness will change only up to twice a year with a winter and summer cover being used, if at all. However, although cover thickness is likely to remain constant for long periods during the year, other factors will tend to maintain a constant internal bed temperature. For example, as an occupant begins to feel too warm in bed they may cover less of their body with the cover, or they may move within the bed. As a result, 
it is reasonable to assume that the thermal and moisture effect will be similar to having a differing thickness of cover.

The thickness of the bed cover is determined for each month by performing an energy balance calculation for the bed with an assumed constant temperature of $34^{\circ} \mathrm{C}$ and a fixed sensible metabolic gain into the occupied bed.

Quantifying the sensible metabolic heat gain into the bed is complicated by the fact that, firstly, it is not the total metabolic heat gain, so radiant heat losses from the head, sensible and latent heat loss through breathing and latent heat loss into the bed due to diffusion of water through the skin has to be accounted for. Secondly, the metabolic heat gains are a function of the thickness of the cover and so the calculation has to iterate the result.

Figure 2 shows the network diagrams for the thermal and moisture calculations.

The thickness of the cover $\left(\mathrm{d}_{\text {cover }}\right)$ is calculated using the following equation derived from an energy balance assuming fixed internal and external temperatures:

$$
d_{\mathrm{cov} e r}=k_{\mathrm{cov} e r}\left[\left(\frac{1}{\frac{2 Q_{b e d}}{\Delta T}-U_{\text {mattress }}}\right)-R_{\text {s. cov } e r}\right]
$$

The sensible metabolic heat gain into the bed $\left(\mathrm{Q}_{\mathrm{bed}}\right)$ is the key variable, not the total metabolic heat gain (M). For sleeping, the total metabolic heat gain is typically 40 $\mathrm{W} / \mathrm{m}^{2}$ of body surface area ${ }^{(10)}$. The total metabolic heat gain $(\mathrm{M})$ is the sum of the 
sensible metabolic heat gains into the bed ( $\left.Q_{b e d}\right)$, radiant heat losses from the uncovered head (R), convective heat losses from the head (C), latent respiration heat losses $\left(E_{\text {re }}\right)$, dry respiration heat losses $(L)$ and heat losses by skin diffusion $\left(E_{d}\right)$.

Therefore,

$$
Q_{b e d}=M-\left(R+C+E_{r e}+L+E_{d}\right)
$$

Each of these separate components are determined within the BED3 model using adapted formulae published by Fanger ${ }^{(10)}$. These adapted formulae have had an appropriate conversion factor (1.163) incorporated to convert from kcal/hour to Watts as follows.

For radiant heat losses from the head $(\mathrm{R})$ :

$$
R=\left(3.95 \times 10^{-8} \cdot A_{\text {head }}\right)\left(\left(T_{\text {head }}+273\right)^{4}-\left(T_{\text {room }}+273\right)^{4}\right)
$$

For convective heat losses from the head (assuming that $\left.\mathrm{T}_{\text {head }}=\mathrm{T}_{\text {bed }}\right)(\mathrm{C})$ :

$$
\begin{aligned}
& C=A_{\text {head }} \cdot h_{c} \cdot \Delta T \\
& \left(\text { where } h_{c}=2.38 \cdot(\Delta T)^{0.25}\right. \text { ) }
\end{aligned}
$$

For latent respiration heat losses $\left(\mathrm{E}_{\mathrm{re}}\right)$ :

$$
E_{\text {re }}=2.67 \times 10^{-3} \cdot M\left(44-\frac{V P_{\text {room }}}{133}\right)
$$


For dry respiration heat losses (L):

$$
L=1.63 \times 10^{-3} \cdot M(\Delta T)
$$

For heat losses by skin diffusion $\left(\mathrm{E}_{\mathrm{d}}\right)$ :

$$
E_{d}=3.07 \times 10^{-3} \cdot A_{b o d y}\left(S V P_{\text {skin }}-V P_{b e d}\right)
$$

These formulae are used to determine, by iteration, the thickness of the bed cover for each of the twelve months of the year. Once the thickness of the cover has been determined BED3 uses a simple thermal and moisture calculation to determine the average temperature and relative humidity in the bed for each month of the year, based upon the flow of heat and moisture upwards through the bed cover and downwards through the mattress.

\subsection{Thermal calculation}

The thermal calculation is made simple due to the fact that the occupied bed temperature is assumed to be $34^{\circ} \mathrm{C}$ (the comfort temperature) and the unoccupied bed temperature is assumed to be the ambient room temperature predicted by the Condensation Targeter II model. The number of hours that the bed is occupied $\left(\mathrm{t}_{\text {occ }}\right)$ is required in the calculation, as indicated in the formula below. We normally assume that the bed is occupied for eight hours per night, although other values can be input in the BED3 model. 


$$
T_{b e d}=\frac{\left(34 \cdot t_{o c c}\right)+\left(T_{a i r} \cdot\left(24-t_{o c c}\right)\right)}{24}
$$

\subsection{Moisture calculation}

The vapour pressure within the core of the occupied bed $\left(\mathrm{VP}_{\text {bed }}\right)$ is calculated using the saturated vapour pressure at skin temperature $\left(\mathrm{SVP}_{\text {skin }}\right)$, the vapour pressure of the air in the room ( $\left.\mathrm{VP}_{\text {room}}\right)$ and vapour resistance values for the body ( $\left.\mathrm{VR}_{\text {body }}\right)$, the mattress ( $\left(\mathrm{VR}_{\text {mattress }}\right)$ and the cover $\left(\mathrm{VR}_{\text {cover }}\right)$ as indicated in the formulae below.

$$
V P_{\text {bed }}=\frac{\left(\frac{S V P_{\text {skin }}}{V R_{\text {body }}}+\frac{V P_{\text {room }}}{V R_{\text {mattress }}}+\frac{V P_{\text {room }}}{V R_{\text {cover }}}\right)}{\left(\frac{1}{V R_{\text {body }}}+\frac{1}{V R_{\text {mattress }}}+\frac{1}{V R_{\text {cover }}}\right)}
$$

It is important to note that the above equation assumes that the vapour resistivity at the surface of the cover is negligible compared to the vapour resistivity of the cover and so it does not appear in the equation.

When the bed is unoccupied, the vapour pressure within the core of the bed is assumed to be the same as the vapour pressure of the room air $\left(\mathrm{VP}_{\text {bed }}=\mathrm{VP}_{\text {room }}\right)$.

Once the occupied and unoccupied vapour pressures have been determined the relative humidity for the occupied bed $\left(\mathrm{RH}_{\text {occ }}\right)$ is determined using the occupied bed temperature $\left(34^{\circ} \mathrm{C}\right)$ and vapour pressure $\left(\mathrm{VP}_{\text {bed }}\right)$ and the relative humidity for the unoccupied bed ( $\left.\mathrm{RH}_{\text {unocc }}\right)$ is determined using the unoccupied bed temperature $\left(\mathrm{T}_{\text {room }}\right)$ and vapour pressure $\left(\mathrm{VP}_{\text {room }}\right)$. 
Finally the 24 hour average bed core relative humidity $\left(\mathrm{RH}_{\text {bed }}\right)$ is determined using the number of hours that the bed is occupied $\left(\mathrm{t}_{\mathrm{occ}}\right)$, as indicated in the formula below.

$$
R H_{b e d}=\frac{\left(R H_{o c c} \cdot t_{o c c}\right)+\left(R H_{u n o c c} \cdot\left(24-t_{o c c}\right)\right)}{24}
$$

Figure 3 shows the monthly BED3 predictions for a typical dwelling in the Thames Valley region of the UK along with the Condensation Targeter II predictions for the bedroom which has been used as inputs to the BED3 model.

\subsection{Validation of the BED3 model}

Long-term monitoring of the environmental conditions in three bedrooms has been carried out using Hobo H8 data loggers manufactured by Onset Computer Corporation (www.onsetcomputer.com). The accuracy of these data loggers for temperature is $\pm 0.7^{\circ} \mathrm{C}$ and for relative humidity is $\pm 5.0 \%$. Conditions of temperature and relative humidity in three locations in each bedroom have been measured every thirty minutes over a period of two years. One data logger was positioned in the bedroom away from the bed, one in the bed, with the transducer removed from the logger casing, directly underneath the occupant and one directly underneath the bed mattress. A fourth data logger was positioned outside of each dwelling collecting simultaneous data for the external climate local to each dwelling.

Data has been collected in the three dwellings between September 2000 and August 2001. The monthly averages of temperature and relative humidity have been determined for both the bedroom conditions and the bed core conditions and these 
have been compared to the BED3 predictions for these three bedrooms. The monthly average measured data for the three dwellings has been compared with the BED3 model predictions.

Figures 4, 5, 6 and 7 show comparisons between monitored and modelled conditions of temperature and relative humidity in the bedroom and in the bed.

The results indicate that the BED3 model predicts the conditions of temperature and relative humidity in the bedroom and in the bed with a high degree of accuracy. The mean deviation between measured and predicted temperatures in the bed is $1.2^{\circ} \mathrm{C}$. The mean deviation between the measured and predicted relative humidity in the bed is $6.2 \%$. On average Condensation Targeter II under-predicts the average conditions of relative humidity in the bedroom and as a result of this BED3 also under-predicts the average relative humidity in the bed. This requires further investigation in both models.

It is also worth noting that the bed core relative humidity, both measured and modelled, is consistently lower than the bedroom relative humidity, which is counterintuitive to many people. However, this can be explained by the fact that although the occupant is producing moisture within the bed, the higher temperature of the occupied bed is a more significant factor, which reduces the relative humidity in the core of the occupied bed. The monitoring of real beds and bedrooms, as part of this research project, has also shown this to be the case. 


\subsection{Sensitivity of the BED3 model}

The sensitivity of the BED3 model has been tested by modifying the input parameters and assessing the impact that these changes have on the predictions of relative humidity in the core of the bed. The input parameters that have been tested include those relating to the occupant and their bed and bedding and to changes made in the fabric and ventilation of the dwelling and occupancy factors such as heating system and controls.

A semi detached dwelling in the Thames valley region, built to the current Building Regulations, has been used as the base case, and typical occupancy levels and moisture production has been assumed. The base case predictions for relative humidity within the core of the bed is $61.2 \%$.

The results of the sensitivity testing of the BED3 model are shown in Figure 8. This shows that the building related input parameters have the greatest impact on the predictions of the bed core relative humidity. Heating pattern, occupancy levels, insulation, ventilation and to a lesser extent demand temperature, all have a significant impact on the predictions of relative humidity ranging between a change of $10 \%$ and $15 \%$.

Interestingly, the assumed size of the head of the bed occupant has a large impact on the predictions. This is due to the assumptions made about the heat and moisture produced from the head (outside of the bed) compared to the rest of the body (inside the bed). A change in the head radius from $0.075 \mathrm{~m}$ to $0.125 \mathrm{~m}$ produces a predicted 
change in bed core relative humidity of nearly $5 \%$. This has a greater impact on bed core relative humidity than drying clothes indoors in this case.

\subsection{Climate change analysis}

Climate change scenarios in the UK have been published by the Climatic Research Unit in Norwich ${ }^{(11)}$. Using this data the Building Research Establishment (BRE) has published climate change scenarios which give an indication of the likely changes in external temperature and moisture levels in the UK in the years 2050 and $2080^{(12)}$. Using this information, the external climatic data in the Condensation Targeter II / BED 3 model has been adjusted to assess the impact of climate change on the risks associated with the house dust mite in beds.

A typical modern semi detached dwelling in London has been modelled during the heating season.

Figures 9 and 10 show the impact of climate change on bed core temperature and relative humidity respectively.

The results show that if the published climate change scenarios are accurate then both the temperature and relative humidity in beds are likely to increase. As a result, the predictions of climate change indicate that the risks associated with the house dust mite are going to increase significantly. 


\subsection{Conclusions}

Both the temperature and relative humidity in a bed are critical factors when determining the population of house dust mites. This is because the temperature impacts on the development time of the house dust mites from the egg to the adult stages of their lifecycle, and the relative humidity impacts on the rate of dehydration and therefore the lifetime of the adult mite. The simple BED3 model provides a mechanism by which a simple sensitivity study can be undertaken to determine the average conditions that will impact on the population of mites. The BED3 model predicts the bed core temperature and relative humidity to a high degree of accuracy, albeit that it tends to under-predict the relative humidity. This may be because the model is not sophisticated enough to account for the bed occupant sweating. This requires further investigation.

The sensitivity study presented here highlights the important role that the building environment plays in the bed environment. It demonstrates the potential for controlling house dust mite populations by environmental means

The BED3 model has the potential to be integrated with a simple population model, which takes the hygrothermal conditions within the bed to predict the average mite population each month. This work is currently been undertaken and will be reported at a later date. In addition, it is clear that house dust mites are exposed to diurnal varying conditions and that the environmental conditions across a bed change from the zone where somebody sleeps to the edge zone where the environment is closer to the room conditions. Mites are able to move to the most favourable environment and ideally this should also be modelled. As a result of this, a three dimensional transient model 
(LECTUS) of a bed has also been developed and has been linked to a population model that models all stages of the house dust mite life cycle and allows for mite movement.

Both models are being further developed and their validity tested in a new EPSRC project (GR/S70678/01). This project involves a major field study involving 60 houses and aims to further validate the BED3 model so that it can be used with greater confidence as a predictive tool. The BED3 model will then be used to determine viable control strategies for a range of UK house types.

\subsection{Acknowledgements}

This research project was funded by the Engineering and Physical Sciences Research Council (EPSRC) (Project GR/M93925/01).

\subsection{References}

1. ISAAC Steering Committee, (1988), Worldwide variations in the prevalance of asthma symptoms: the International Study of Asthma and Allergies in Childhood (ISAAC), European Respiratory Journal, 12: 315 - 335.

2. Jansen C et al, (2001), The European Community Respiratory Health Survey: what are the main results so far?, European Respiratory Journal, 18: 598 - 611.

3. Korsgaard J, (1983) House Dust Mites and absolute indoor humidity, Allergy, 38: $85-92$. 
4. Harving $\mathrm{H}$ et al, (1991), House Dust Mite allergy and anti-mite measures in the indoor environment, Allergy, 46: supplement 11: 33 - 38.

5. Pretlove S E C, Ridley I, Horwood J A, Leung B, Cox P, Thomson D, Baker N, Crowther D, Oreszczyn T, (2001), A combined transient hygrothermal and population model of house dust mites in beds, IAQ 2001: Moisture, Microbes and Health Effects: Indoor Air Quality and Moisture in Buildings, ASHRAE, San Francisco, November $4^{\text {th }}-7^{\text {th }}$.

6. $\quad$ Oreszczyn T and Pretlove S E C, (1999), Condensation Targeter II: Modelling surface relative humidity to predict mould growth in dwellings, Build. Serv. Eng. Res. Tech. 20 (3) $143-153$

7. Anderson B R, Chapman P F, Cutland N G, Dickson C M, Doran S M, Iles P J and Shorrock L D, (1997) BREDEM-12 Model description, Building Research Establishment (BRE).

8. Loudon A G, (1971) The effects of ventilation and building design factors on the risk of condensation and mould growth in dwellings, Building Research Station (BRS) CP 31/71

9. Pretlove S E C, (2000), Predicting relative humidity in UK dwellings, PhD Thesis, University of London, March 2000. 
10. Fanger P O, (1970), Thermal Comfort: Analysis and Applications in Environmental Engineering, Mc Graw-Hill Book Company, London.

11. Hulme M \& Jenkins G J, (1998) Climate change scenarios for the UK: scientific report, UKCIP Technical Report No 1, Climatic Research Unit, Norwich.

12. Graves H M \& Phillipson M C, (2000), Potential implications of climate change in the Built Environment, Foundation for the Built Environment (FBE), Building Research Establishment (BRE), East Kilbride. 


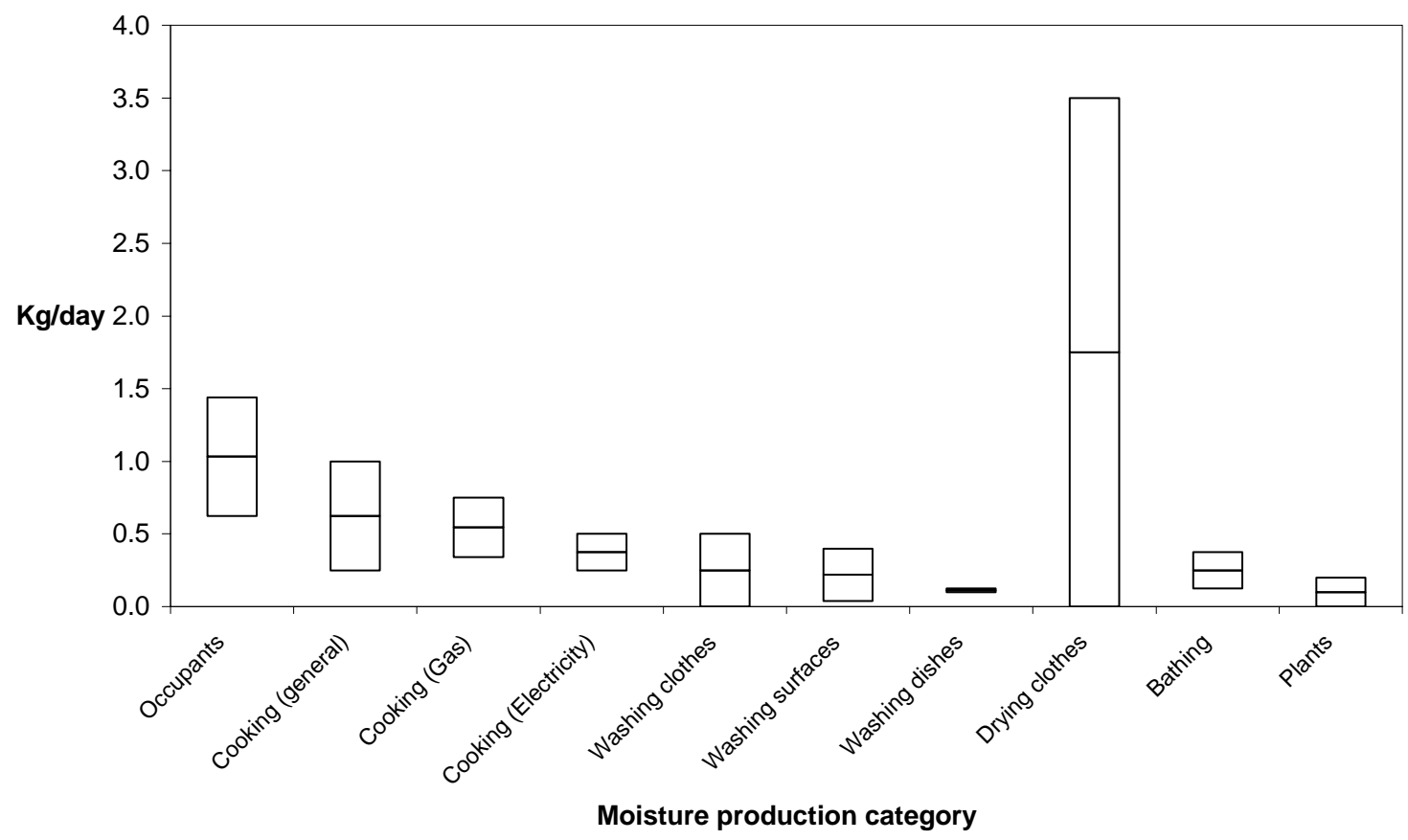

Figure 1: Typical range of moisture production rates for each moisture production category per person (kg/day) 
Thermal:

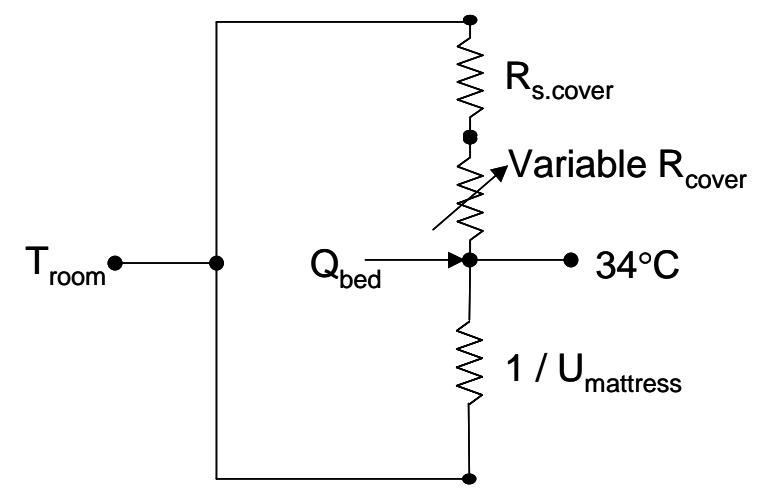

Moisture:

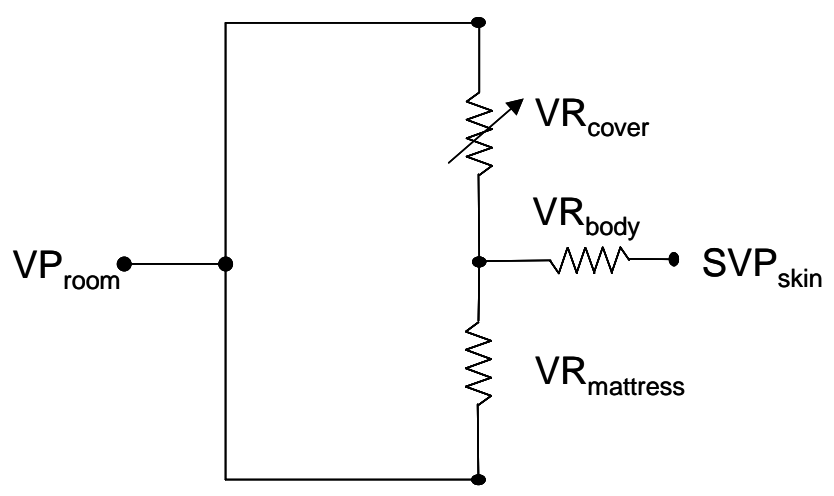

Figure 2: Network diagrams for the thermal and moisture calculations 


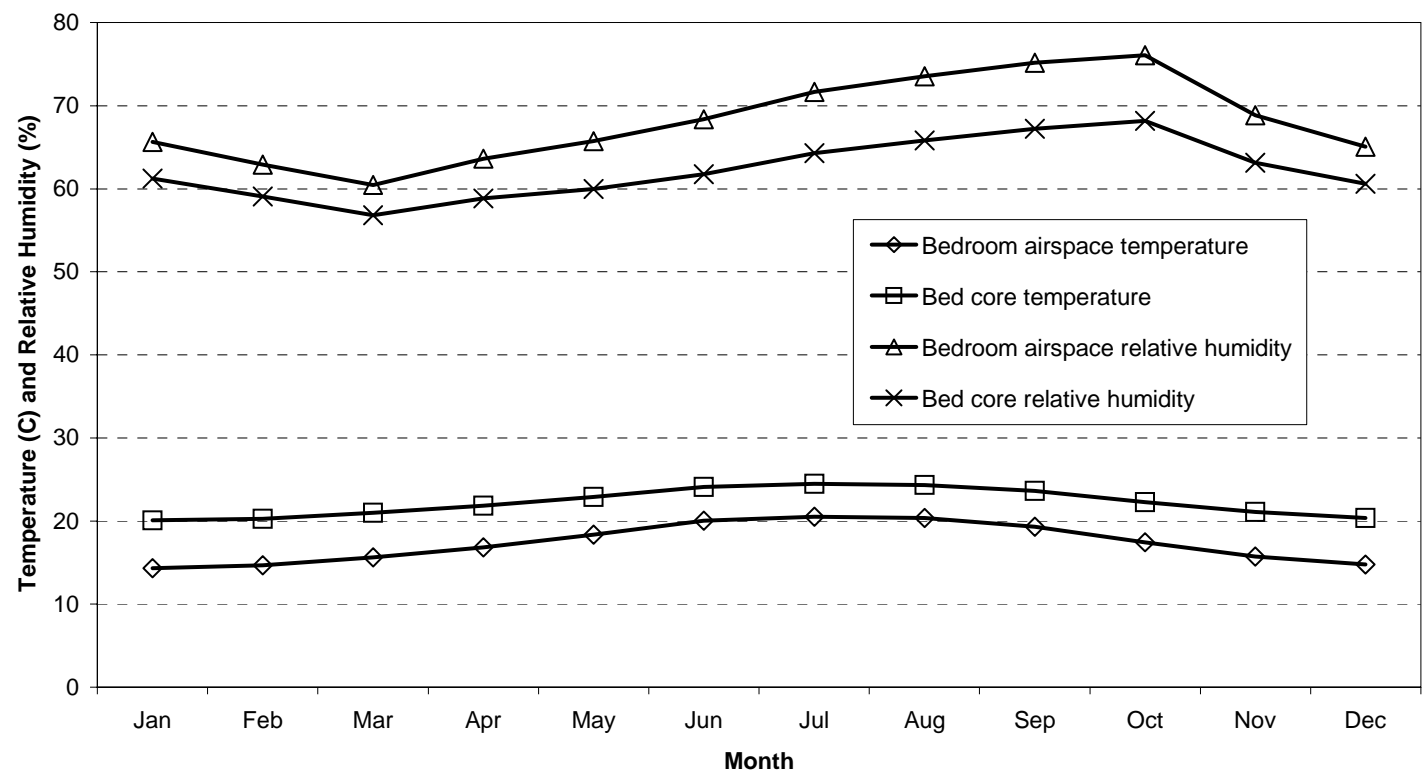

Figure 3: Monthly BED3 predictions for a typical dwelling in the Thames Valley region of the $\mathrm{UK}$. 


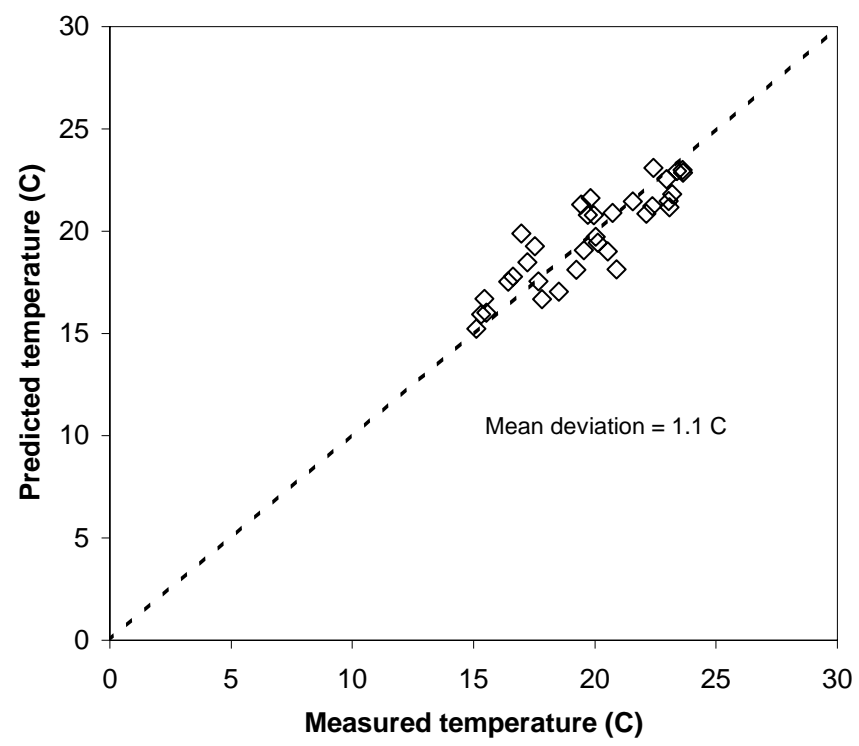

Figure 4: Comparison between monitored and modelled temperature in the bedroom. 


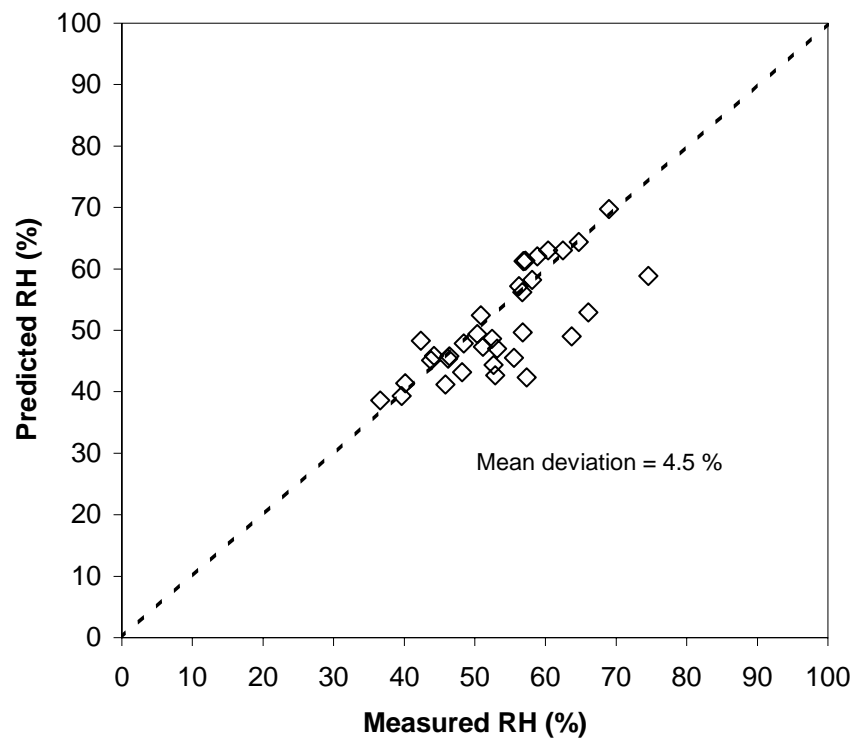

Figure 5: Comparison between monitored and modelled relative humidity in the bedroom. 


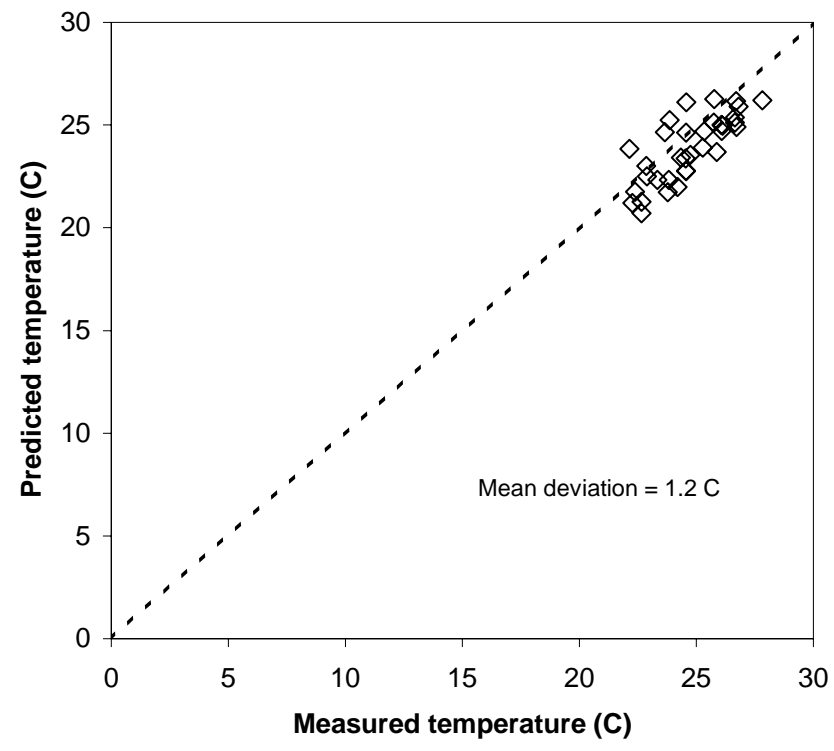

Figure 6: Comparison between monitored and modelled temperature in the bed. 


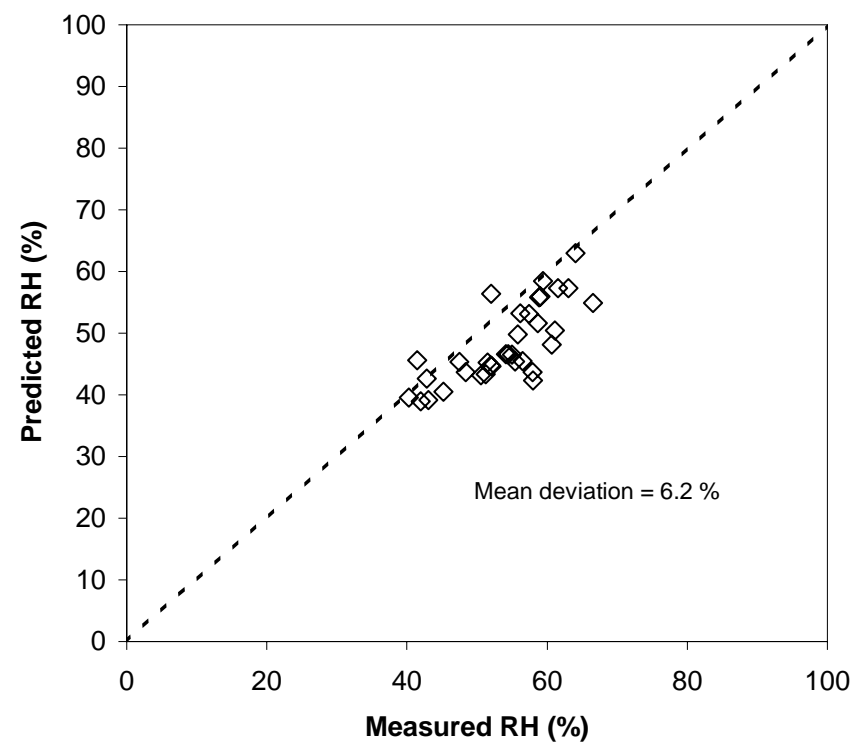

Figure 7: Comparison between monitored and modelled relative humidity in the bed. 


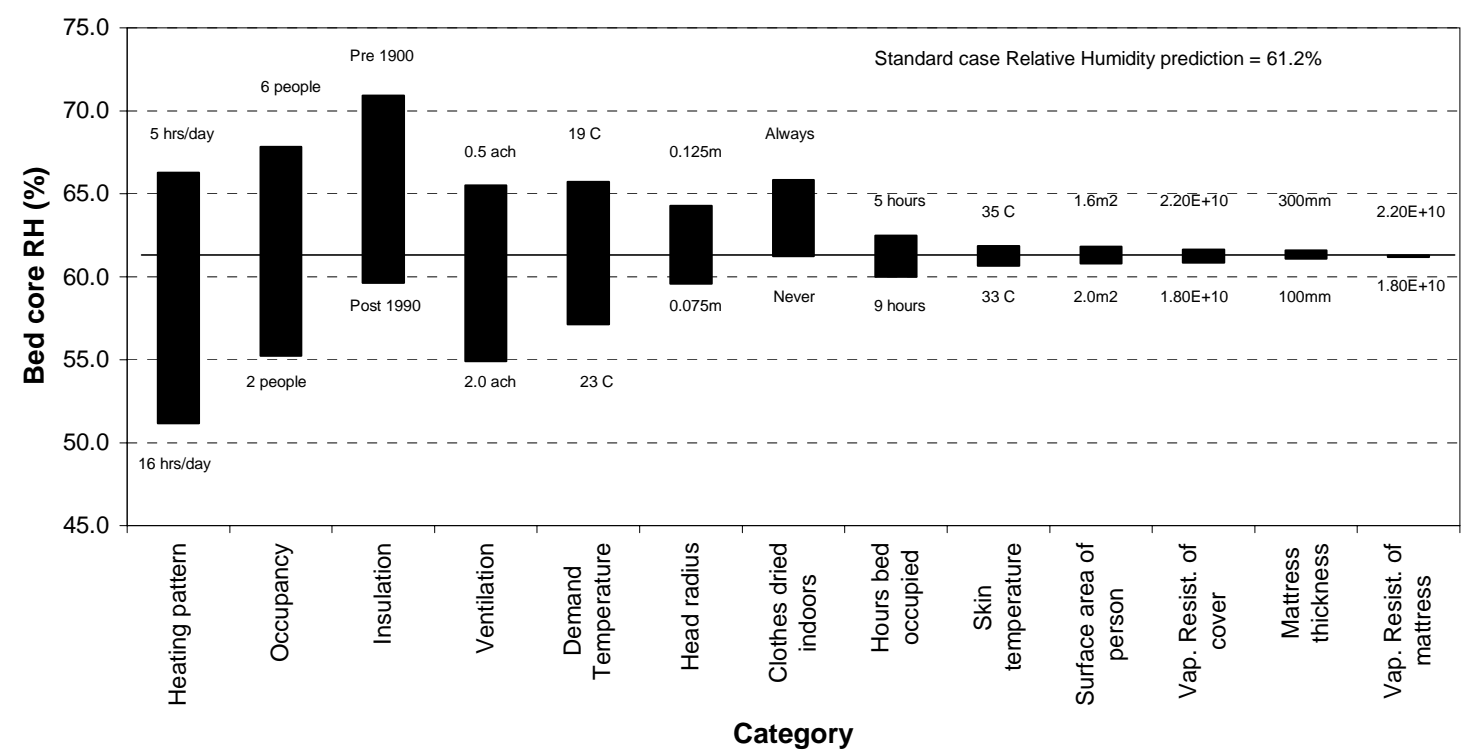

Figure 8: Sensitivity of bed core relative humidity to variations in input parameters of the BED3 model. 


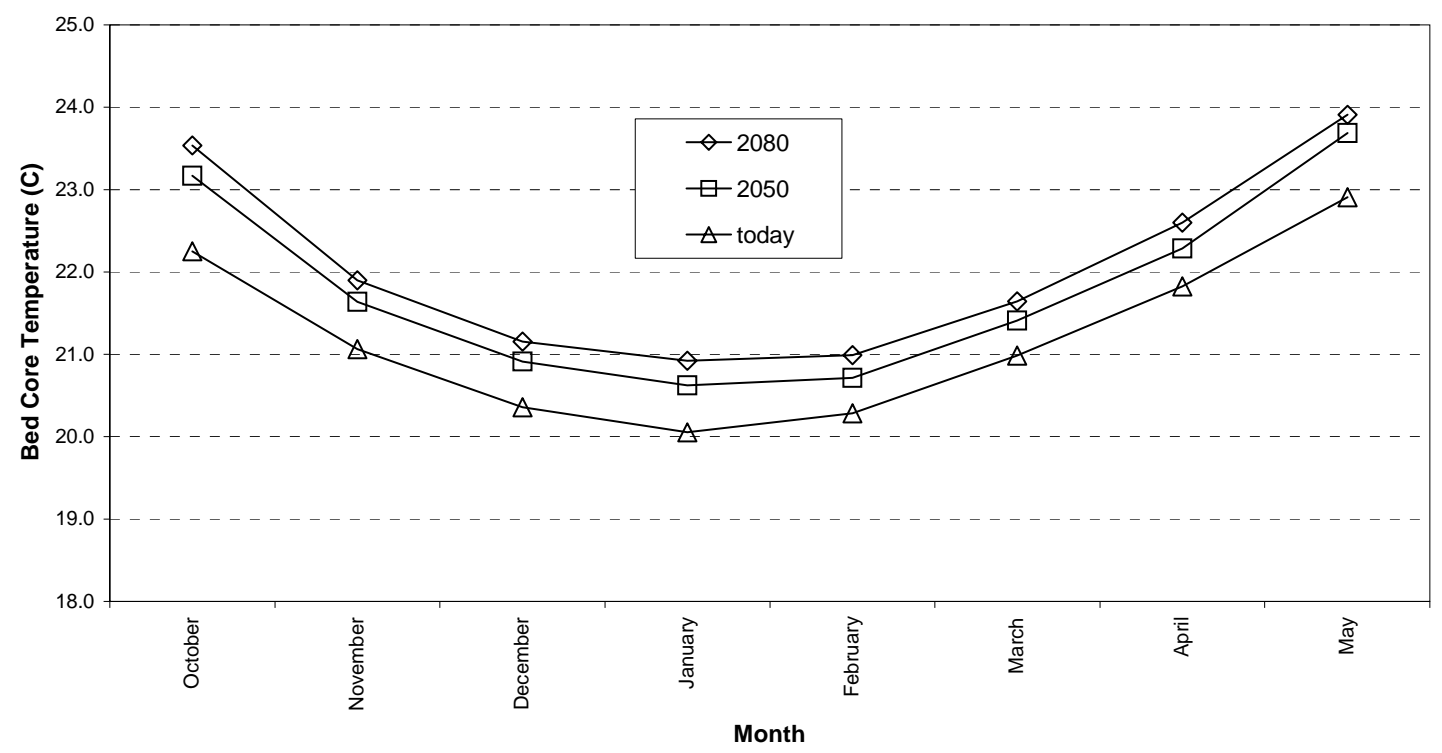

Figure 9: Impact of climate change on bed core temperature. 


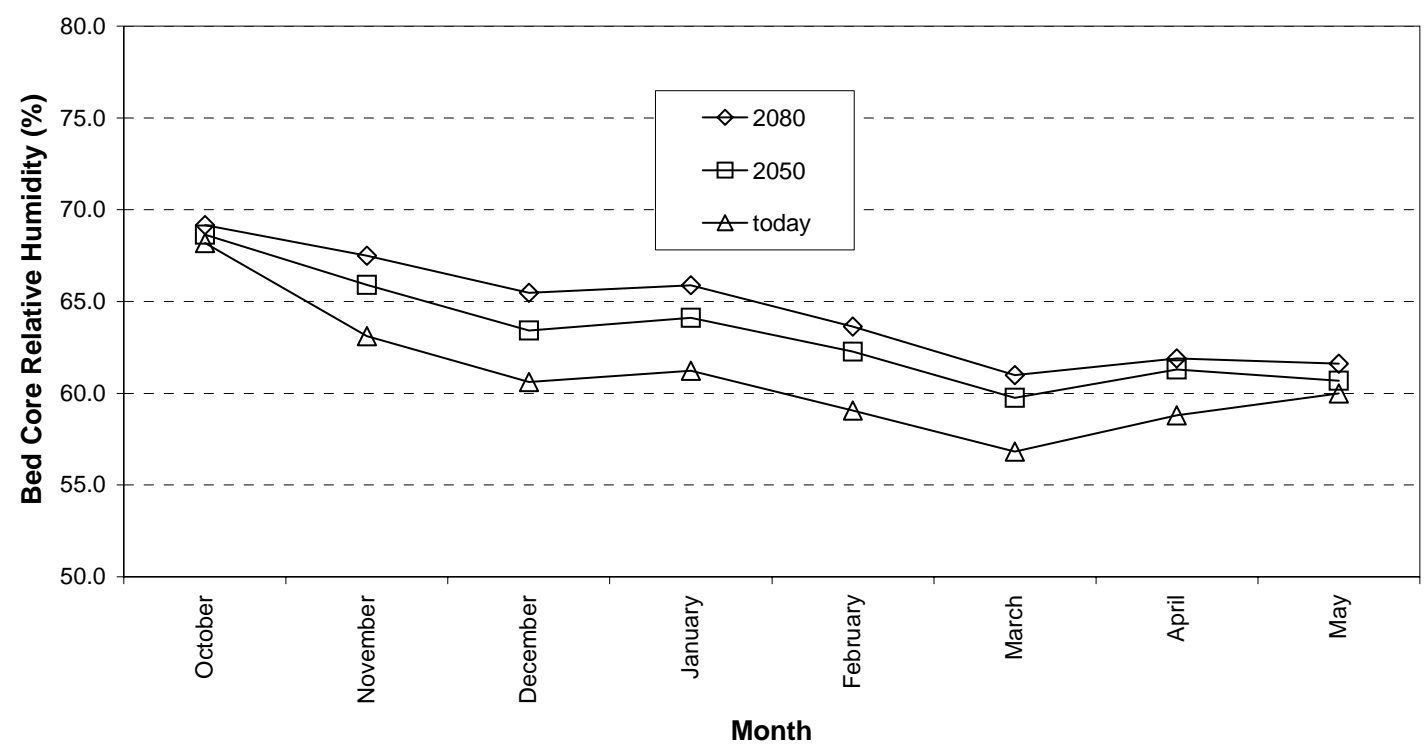

Figure 10: Impact of climate change on bed core relative humidity. 